\title{
Single early instillation of mitomycin $C$ and urinary alkalinization in low-risk non-muscle-invasive bladder cancer: a preliminary study
}

This article was published in the following Dove Press journal:

Drug Design, Development and Therapy

27 December 2012

Number of times this article has been viewed

\author{
Hamit Ersoy \\ Muhammet Yaytokgil \\ Ahmet Nihat Karakoyunlu \\ Hikmet Topaloglu \\ Levent Sagnak \\ Hakki Ugur Ozok \\ Department of Urology, Diskapı \\ Yildirim Beyazit Training and Research \\ Hospital, Ministry of Health, Ankara, \\ Turkey
}

Background: The purpose of this study was to determine the effectiveness of a single early instillation of mitomycin C (MMC) after transurethral resection of bladder tumor (TURBT) together with urinary alkalinization in patients with low-risk non-muscle-invasive bladder cancer (NMIBC).

Methods: Between February 2006 and November 2010, patients diagnosed as having a primary bladder tumor were randomized into standard and optimized treatment groups. The treatment groups were formed prospectively from patients with NMIBC according to results of pathological examination postoperatively, whereas the control group was formed retrospectively. Patients in the standard group $(n=11)$ were given intravesical MMC $40 \mathrm{mg}$ in the first 6 hours after TURBT, while the patients in the optimized group $(n=15)$ underwent urinary alkalinization prior to MMC. In the control group $(n=23)$, no drug treatment was given. The patients were followed after surgery at months 3 and 12, and then annually for the first 5 years using cystoscopy and ultrasound. Time to recurrence and recurrence-free survival rates were calculated.

Results: There were no statistically significant differences between the standard and optimized groups, between the control and optimized groups, or between the control and standard groups in terms of mean recurrence-free survival rates $(P=0.132,0.645$, and 0.173 , respectively). The mean time to recurrence was 34.8 (range 28.5-41.1) months in the optimized group and 51.8 (range 44.3-59.2) months in the control group. There was no recurrence during the follow-up period in the standard group.

Conclusion: The results of this preliminary study could not demonstrate the efficacy of urinary alkalinization before a single dose of early MMC following TURBT to increase the effectiveness of the MMC, so we did not continue the study further.

Keywords: alkalinization, bladder, mitomycin C, tumor

\section{Introduction}

Non-muscle-invasive bladder cancer (NMIBC) generally has a good prognosis. Nevertheless, the recurrence rate is $30-80 \%$ and the muscle-invasive disease develops within five years in $1-45 \%$ of the cases. ${ }^{1,2}$ The goal of treatment is to eliminate the disease, prevent its recurrence, and improve the prognosis. One of the theories advanced to explain tumor recurrence is development of new tumors in tumor cells remaining after inadequate resection. Another theory is seeding of tumor cells in damaged portions of the mucosa, resulting in tumor recurrence. ${ }^{3,4}$ Therefore, intravesical therapy used in the early period could help to prevent tumor recurrence by eliminating floating tumor cells or residual neoplastic tissue. ${ }^{5-7}$ In a series of randomized studies, it was shown that treatment with a cytotoxic agent, such as epirubicin or mitomycin $\mathrm{C}$ (MMC) after
Correspondence: Hakki Ugur Ozok Kardelen Mah 2066, sok Siyasal-2 Sit 83 Batıkent, Yenimahalle, Ankara 06370 Turkey

Tel +905422424660

Fax+90 31 22552086

Email drozok@gmail.com
Drug Design, Development and Therapy 2013:7 I-6

(C) 2013 Ersoy et al, publisher and licensee Dove Medical Press Ltd. This is an Open Access article which permits unrestricted noncommercial use, provided the original work is properly cited.
Dovepress

http://dx.doi.org// 0.2147/DDDT.S3954| 
transurethral resection of bladder tumor (TURBT) decreases the risk of relapse.$^{8-17}$ Nowadays, single instillation of chemotherapy is used in the first 6 hours after TURBT to reduce the likelihood of recurrence in low-risk NMIBC, as recommended in the European Association of Urology guidelines for treatment of bladder cancer. ${ }^{18}$ In studies aiming to increase the effectiveness of intravesical chemotherapy, the most discussed methods are reduction of the volume of MMC solvent, reducing the amount of residual urine, fluid restriction to reduce production of urine, and urinary alkalinization. ${ }^{19}$ The effect of urinary alkalinization on intracavitary MMC as maintenance therapy has been evaluated in other studies, but there is no study reporting on early single instillation of MMC. ${ }^{20,21}$

In this prospective study, our objective was to determine the effectiveness of early single instillation of MMC treatment together with urinary alkalinization in patients with low-risk NMIBC, diagnosed on the basis of pathology results and tumor properties, on increasing the effect of MMC, on time to relapse, and on recurrence rates.

\section{Materials and methods}

Between February 2006 and November 2010, 53 patients with a primary bladder tumor treated in our department by transurethral resection and single instillation of MMC were randomized into standard and optimized treatment groups. The patients, who were diagnosed to have low-risk NMIBC post surgery depending on tumor pathology, number, and size (TaG1, solitary, tumor size $<3 \mathrm{~cm}$ ), were prospectively enrolled in the optimized group. Patients with medium-risk and high-risk NMIBC, those with muscle-invasive bladder cancer, and those with suspected bladder perforation who could not be treated with MMC were excluded from the study. The control group was established retrospectively from patients with low-risk uroepithelial bladder cancer who had previously undergone TURBT without MMC treatment. Early single instillation of MMC is now the standard of care recommended in the guidelines, and all these patients had been treated prior to the current guidelines. In total, 49 patients with a diagnosis of primary bladder tumor treated with TURBT and with records of regular follow-up in the postoperative period were included as the low-risk group. There were 11 patients in the standard treatment group, 15 in the optimized treatment group, and 23 in the control group. The pathological type of bladder cancer was predominantly uroepithelial in all three groups. Approval of the local ethics committee was obtained, and written informed consent forms were taken from patients before surgery.
The patients in the standard treatment group received $40 \mathrm{mg}$ of intracavitary MMC diluted with $40 \mathrm{~mL}$ of sterile saline, given into a completely empty bladder in the first 6 hours postoperatively via a Foley catheter inserted during the operation, and the solution was kept in the urinary bladder for 2 hours. The patients in the optimized group underwent urinary alkalinization prior to administration of MMC. For alkalinization, $1.3 \mathrm{~g}$ of sodium bicarbonate was given orally the night before surgery, on the morning of surgery, and 30 minutes prior to administration of MMC, in three doses. Patients in both the standard and optimized groups received $40 \mathrm{mg}$ of MMC in the same way. In the control group, no drugs were given in the first 6 hours.

The patients were followed after surgery at months 3 and 12 , then annually for the first 5 years by cystoscopy. In addition, patients with macroscopic or microscopic hematuria underwent ultrasound and cystoscopy. Detection of bladder tumors was considered as recurrence. Urinary $\mathrm{pH}$ was measured the night before and just prior to surgery in both the standard and optimized groups. There were no data for the control group.

The mean time to recurrence was calculated from the date of surgery to first recurrence in the control group and recorded in the patient files as "months" for both the standard and optimized groups. In addition, the groups were compared separately with respect to pathological features, demographic characteristics, and related environmental risk factors.

\section{Statistical analysis}

The data analysis was performed using the Statistical Package for the Social Sciences version 11.5 for Windows (SPSS Inc, Chicago, IL). Descriptive statistics for continuous variables were expressed as the mean \pm standard deviation or median (minimum-maximum), and categorical variables were given as number of cases and percentages.

The relationship between recurrence-free survival rate and average life expectancy associated with the categorical variables was assessed by Kaplan-Meier survival analysis using the log-rank test. For each variable, survival rates at 1,3 , and 5 years, median survival time, and $95 \%$ confidence intervals were calculated. The effect of the continuous variables on recurrence-free survival was evaluated using univariate Cox proportional hazards regression analysis. Hazard ratios and $95 \%$ confidence intervals were calculated for each variable. A value of $P<0.05$ was considered to be statistically significant for the results.

\section{Results}

The patients in the three treatment groups were compared with respect to demographic characteristics, tumor size, 
duration of follow-up, occupational risk factors, and smoking history. There were no statistically significant differences between the groups in this respect that may have affected the results of treatment (Table 1).

Pre-alkalinization urinary $\mathrm{pH}$ values (night before surgery) were compared with post-alkalinization urinary $\mathrm{pH}$ values (just before surgery) in the optimized and standard groups. There were no data available for the control group. Mean pre-alkalinization and post-alkalinization $\mathrm{pH}$ values were $5.88 \pm 0.71$ and $6.40 \pm 0.50$ versus $5.88 \pm 0.63$ and $5.88 \pm 0.57$ in the optimized and standard groups, respectively. The increase in mean urinary $\mathrm{pH}$ value was statistically significant in the optimized group $(P=0.005)$, but there was no statistically significant change in the standard group $(P=0.750)$.

The effects of the variables in Table 1, on recurrence-free survival rates were assessed individually. The median age of the patients included in the study was 61 (range 25-84) years, and was found to have no effect on mean recurrence-free survival rate $(P=0.720)$. Forty-four of the 49 patients included were male. The recurrence-free survival rate in these men was $90.9 \%$ and $85.9 \%$, respectively, at 1 and 3 years, while the recurrence-free survival rate of the five female patients was $100 \%$ and $66.7 \%$, respectively, at 1 and 3 years. There was no significant difference between the genders in this regard (Table 2).

Survival of patients with known occupational risk factors was $75 \%$ at 1 and 3 years, whereas patients without occupational risk factors had recurrence-free survival rates of $93.3 \%$ and $85.8 \%$ at 1 and 3 years, respectively. The difference was not statistically significant (Table 2).

Thirty-nine patients with a history of smoking had recurrence-free survival rates of $89.7 \%, 84.2 \%$, and $84.2 \%$ at 1,3 , and 5 years, respectively. The 10 patients with no history of smoking had recurrence-free survival rates of $100 \%, 85.7 \%$, and $85.7 \%$ at 1,3 , and 5 years, respectively. This difference was not statistically significant (Table 2). The overall recurrence-free survival rates for all patients was $91.8 \%, 84.7 \%$ and $84.7 \%$ at 1,3 and 5 years, respectively (Figure 1 and Table 3). The recurrence-free survival rates of the standard group at 1, 3, and 5 years were $100 \%$. In the optimized group, these rates were $86.7 \%, 79.4 \%$, and $79.4 \%$ at 1,3 , and 5 years, respectively. In the control group, the recurrence-free survival rates were $91.3 \%, 82.6 \%$, and $82.6 \%$, at 1,3 , and 5 years, respectively. When the three groups were compared in terms of mean recurrence-free survival rates, no statistically significant difference was found (Table 3 ). The mean time to recurrence was compared between the study groups, and was 34.8 (range 28.5-41.1) months in the optimized group, and 51.8 (range 44.3-59.2) months in the control group, respectively. There was no recurrence during the follow-up period in the standard group (Table 3 ).

\section{Discussion}

The groups had similar characteristics and were evaluated in terms of recurrence-free survival rate, time to recurrence, tumor size, demographic data such as age and gender, and risk factors such as smoking and occupational hazards, which might have an effect on the likelihood of recurrence. No statistically significant difference was found between the three treatment groups with respect to recurrence-free survival and time to recurrence.

With regard to urinary alkalinization, the European Association Urology guidelines refer to the Phase III study by $\mathrm{Au}$ et al, who reported that adaptation of urinary $\mathrm{pH}$, reduced urinary output, and buffering of the intravesical

Table I Demographic and clinical characteristics of patients in treatment groups

\begin{tabular}{|c|c|c|c|c|}
\hline Variables & $\begin{array}{l}\text { Standard } \\
\mathbf{n}=\mathbf{I} \mid\end{array}$ & $\begin{array}{l}\text { Optimized } \\
n=15\end{array}$ & $\begin{array}{l}\text { Control } \\
n=23\end{array}$ & $P$ value \\
\hline Age, years (mean $\pm S D)$ & $59.3 \pm 14.9$ & $63.5 \pm 15.0$ & $61.9 \pm 10.2$ & 0.716 \\
\hline Gender & & & & 0.395 \\
\hline Male, n (\%) & $9(81.8)$ & $13(86.7)$ & $22(95.7)$ & \\
\hline Female, n (\%) & $2(18.2)$ & $2(13.3)$ & I (4.3) & \\
\hline Tumor size, mm (mean \pm SD) & $18.3 \pm 7.9$ & $19.1 \pm 8.4$ & $19.4 \pm 7.8$ & 0.858 \\
\hline Duration of follow-up, months, median (range) & $51(12-60)$ & $50(12-59)$ & $54(38-60)$ & 0.815 \\
\hline Occupational risk factors & & & & 0.264 \\
\hline None, n (\%) & $9(8 \mid .8)$ & $13(86.7)$ & $18(78.2)$ & \\
\hline Present, n (\%) & $2(18.2)$ & $2(13.3)$ & $5(2 \mid .8)$ & \\
\hline History of smoking & & & & 0.124 \\
\hline None, n (\%) & $4(36.4)$ & $4(26.7)$ & $2(8.7)$ & \\
\hline Present, n (\%) & $7(63.6)$ & II (73.3) & 21 (9l.3) & \\
\hline
\end{tabular}

Abbreviation: SD, standard deviation. 
Table 2 Risk factors that may have impact on recurrence-free survival

\begin{tabular}{|c|c|c|c|c|c|c|}
\hline \multirow[t]{2}{*}{ Variables } & \multicolumn{3}{|l|}{ RFSR (\%) } & \multirow{2}{*}{$\begin{array}{l}\text { Mean time to recurrence } \\
(95 \% \mathrm{Cl})\end{array}$} & \multirow[t]{2}{*}{ Log-rank } & \multirow[t]{2}{*}{$P$ value } \\
\hline & One-year & Three-year & Five-year & & & \\
\hline Gender & & & & & 0.09 & 0.769 \\
\hline Male $(n=44)$ & 90.9 & 85.9 & 85.9 & $53.0(47.7-58.2)$ & & \\
\hline Female $(n=5)$ & 100.0 & 66.7 & & $44.9(28.6-61.1)$ & & \\
\hline Occupational risk factors & & & & & 0.77 & 0.382 \\
\hline None $(n=40)$ & 93.3 & 85.8 & 85.8 & $53.3(48.3-58.3)$ & & \\
\hline Present $(n=9)$ & 75.0 & 75.0 & & $40.7(23.2-58.2)$ & & \\
\hline History of smoking & & & & & 0.21 & 0.645 \\
\hline None $(n=10)$ & 100.0 & 85.7 & 85.7 & $54.9(45.8-64.1)$ & & \\
\hline Present $(n=39)$ & 89.7 & 84.2 & 84.2 & $52.1(46.3-57.9)$ & & \\
\hline
\end{tabular}

Abbreviations: $\mathrm{Cl}$, confidence interval; RFSR, recurrence-free survival rate.

solution all contribute to reduction in the recurrence rate. ${ }^{19}$ Moreover, in another randomized trial, it is documented that the urinary drug concentration is more important than the duration of treatment. ${ }^{21}$ In light of these data, which all still need to be validated, the patient is asked to restrict their water intake on the morning of instillation, and it is recommended to dissolve the drug in an optimally buffered solution. On the other hand, in the American Urological Association guidelines, although it is stated that the optimal method of administration of MMC is unclear, reference is again made to the study by Au et al, and dehydration, alkalinization, dose concentration, and bladder evacuation are recommended. ${ }^{19}$ There are no recommendations in the National Comprehensive Cancer Network guidelines regarding adaptation of urinary $\mathrm{pH}$.

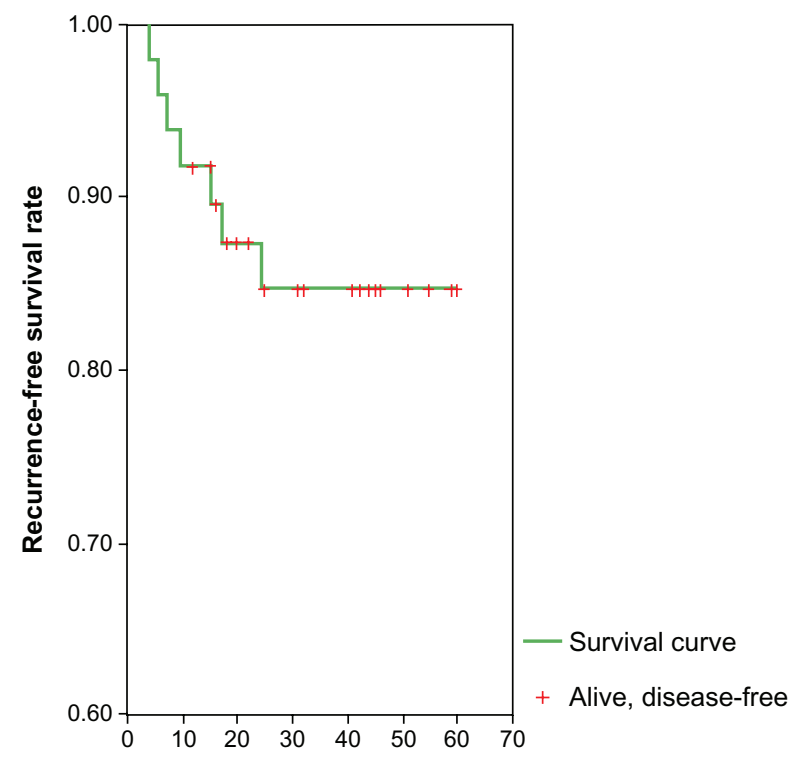

Duration of follow-up (months)

Figure I Kaplan-Meier curve showing rate of recurrence-free survival in all patients.
There are no studies in the literature on the use of urinary alkalinization in patients with primary bladder tumors, in addition to early postoperative single-dose instillation of MMC. The effectiveness of urinary alkalinization has been questioned in studies investigating induction treatment with MMC. In the study by Au et al, performed on behalf of the international MMC consortium, it was predicted that when the physiological parameters of urine are under control, the MMC reaches higher concentrations in urine and therefore in the tumor. ${ }^{19}$ When the results of their study are compared with ours, their study showed a longer period of time to relapse and a greater disease-free survival rate in the optimized group. On the other hand, unlike our study, some measures other than urinary alkalinization were taken into account, including an increased dose of MMC, diluent volume reduction, and restriction of fluid. Therefore, the overall result obtained represents the sum of these individual measures. However, in our study, the only difference between the standard and optimized groups was in alkalinization of urine, and only the effectiveness of urinary alkalinization was monitored. In the Au et al study, optimization for induction therapy was used in patients with a high-risk primary tumor or recurrence, whereas in our study, only early postoperative instillation of a single dose was used in low-risk patients with primary bladder tumors. Therefore, in our study, the effect of urinary alkalinization was only measured after instillation of a single dose of MMC, whereas in the study by Au et al, the cumulative effect of urinary alkalinization over an average period of 6 weeks before each MMC instillation may be responsible for the positive outcomes in the optimized group.

The effect of $\mathrm{pH}$ on the activity of MMC is another controversial issue. Au et al alkalinized the urine to stabilize the MMC. Maeda et $\mathrm{al}^{22}$ also showed that both the stability and activity of $\mathrm{MMC}$ are $\mathrm{pH}$-dependent, and that a urinary $\mathrm{pH}$ 
Table 3 Recurrence-free survival rates and median time to recurrence in treatment groups

\begin{tabular}{|c|c|c|c|c|c|c|}
\hline \multirow[t]{2}{*}{ Groups } & \multicolumn{3}{|l|}{ RFSR (\%) } & \multirow{2}{*}{$\begin{array}{l}\text { Mean time to recurrence } \\
(95 \% \mathrm{CI})\end{array}$} & \multirow[t]{2}{*}{ Log-rank } & \multirow[t]{2}{*}{$P$ value } \\
\hline & One-year & Three-year & Five-year & & & \\
\hline Standard $(n=I I)$ & 100.0 & 100.0 & 100.0 & - & & \\
\hline Optimized $(n=15)$ & 86.7 & 79.4 & 79.4 & $34.8(28.5-4 I . I)$ & & \\
\hline Control $(n=23)$ & 91.3 & 82.6 & 82.6 & $51.8(44.3-59.2)$ & & \\
\hline General $(n=49)$ & $91.8^{\mathrm{a}, \mathrm{b}}$ & $84.7^{\mathrm{a}, \mathrm{c}}$ & $84.7^{\mathrm{b}, \mathrm{c}}$ & $52.7(47.7-57.7)$ & 2.43 & 0.297 \\
\hline
\end{tabular}

Notes: a Between standard and optimized groups $(P=0.132)$; between standard and control groups $(P=0.173)$; cbetween optimized and control groups $(P=0.645)$.

Abbreviations: $\mathrm{Cl}$, confidence interval; RFSR, recurrence-free survival rate.

greater than 5.5 heralds a good prognosis in MMC-treated patients. However, in in vitro studies, MMC has been shown to be more cytotoxic at acidic $\mathrm{pH}$ levels. ${ }^{23}$ In contrast, although the bladder tumor cells had a $\mathrm{pH}$-dependent response in monolayer cultures, this reaction could not be demonstrated in multilayer cultures. ${ }^{24}$ In our study, it was demonstrated that effective urinary alkalinization could be achieved in the optimized group. Nevertheless, a further contribution of preoperative urinary alkalinization to the benefits of early single-dose MMC instillation could not be demonstrated in terms of recurrence-free survival rate or time to recurrence.

This study could not demonstrate the efficacy of urinary alkalinization before early single-dose MMC instillation following TURBT in improving the effectiveness of MMC. However, although our study has some important limitations, including the small number of patients in the treatment and control groups, and a short follow-up period, it may have made a considerable contribution to the relevant literature, being an early study of the use of urinary alkalinization, in addition to single early MMC instillation following TURBT in patients with NMIBC.

\section{Conclusion}

The results of this preliminary study did not demonstrate the efficacy of urinary alkalinization in increasing the effectiveness of a single dose of early MMC instillation following TURBT, and discouraged us from continuing the practice. Studies with larger numbers and longer follow-up periods are needed to confirm or refute our findings.

\section{Disclosure}

The authors report no conflicts of interest in this work.

\section{References}

1. Fitzpatrick JM, West AB, Butler MR, Lane V, O’Flynn JD. Superficial bladder tumors (stage pTa, grades 1 and 2): the importance of recurrence pattern following initial resection. J Urol. 1986;135:920-922.

2. Schrier BP, Hollander MP, van Rhijn BW, Kiemeney LA, Witjes JA. Prognosis of muscle-invasive bladder cancer: difference between primary and progressive tumours and implications for therapy. Eur Urol. 2004;45: 292-296.
3. Bouffioux C, Kurth $\mathrm{KH}$, Bono A, et al. Intravesical adjuvant chemotherapy for superficial transitional cell bladder carcinoma: results of 2 European Organization for Research and Treatment of Cancer randomized trials with mitomycin $\mathrm{C}$ and doxorubicin comparing early versus delayed instillations and short-term versus long-term treatment. European Organization for Research and Treatment of Cancer Genitourinary Group. J Urol. 1995;153:934-941.

4. Soloway MS, Masters S. Urothelial susceptibility to tumor cell implantation: influence of catheterization. Cancer. 1980;46:1158-1163.

5. Pan JS, Slocum HK, Rustum YM, Greco WR, Gaeta JF, Huben RP. Inhibition of implantation of murine bladder tumor by thiotepa in cauterized bladder. $J$ Urol. 1989;142:1589-1593.

6. Pode D, Alon Y, Horowitz AT, Vlodavsky I, Biran S. The mechanism of human bladder tumor implantation in an in vitro model. J Urol. 1986; 136:482-486.

7. Türkeri L. Yüzeyel mesane kanserinin tedavisinde postoperatif erken dönemde tek doz intravezikal kemoterapinin yeri. [The role of a single dose intravesical chemotherapy in early postoperative period in the treatment of superficial bladder cancer]. Üroonkoloji Bülteni. 2003;1:14-17. Turkish.

8. Burnand KG, Boyd PJ, Mayo ME, Shuttleworth KE, Lloyd-Davies RW. Single dose intravesical thiotepa as an adjuvant to cystodiathermy in the treatment of transitional cell bladder carcinoma. Br J Urol. 1976;48:55-59.

9. Abrams PH, Choa RG, Gaches CG, Ashken MH, Green NA. A controlled trial of single dose intravesical adriamycin in superficial bladder tumours. Br J Urol. 1981;53:585-587.

10. Zincke H, Utz DC, Taylor WF, Myers RP, Leary FJ. Influence of thiotepa and doxorubicin instillation at time of transurethral surgical treatment of bladder cancer on tumor recurrence: a prospective, randomized, double-blind, controlled trial. J Urol. 1983;129:505-509.

11. Oosterlinck W, Kurth KH, Schröder F, Bultinck J, Hammond B, Sylvester R. A prospective European Organization for Research and Treatment of Cancer Genitourinary Group randomized trial comparing transurethral resection followed by a single intravesical instillation of epirubicin or water in single stage Ta, T1 papillary carcinoma of the bladder. J Urol. 1993;149:749-752.

12. Tolley DA, Parmar MK, Grigor KM, et al. The effect of intravesical mitomycin $\mathrm{C}$ on recurrence of newly diagnosed superficial bladder cancer: a further report with 7 years of follow up. J Urol. 1996;155: 1233-1238.

13. Ali-el-Dein B, Nabeeh A, el-Baz M, Shamaa S, Ashamallah A. Singledose versus multiple instillations of epirubicin as prophylaxis for recurrence after transurethral resection of pTa and pT1 transitional-cell bladder tumours: a prospective, randomized controlled study. Br J Urol. 1997;79:731-735.

14. Solsona E, Iborra I, Ricós JV, Monrós JL, Casanova J, Dumont R. Effectiveness of a single immediate mitomycin $\mathrm{C}$ instillation in patients with low risk superficial bladder cancer: short and long-term followup. J Urol. 1999;161:1120-1123.

15. Rajala P, Kaasinen E, Raitanen M, Liukkonen T, Rintala E; Finnbladder Group. Perioperative single dose instillation of epirubicin or interferonalpha after transurethral resection for the prophylaxis of primary superficial bladder cancer recurrence: a prospective randomized multicenter study - FinnBladder III long-term results. J Urol. 2002;168: 981-985. 
16. Okamura K, Ono Y, Kinukawa T, et al; Nagoya University Urological Oncology Group. Randomized study of single early instillation of (2"R)-4'-O-tetrahydropyranyl-doxorubicin for a single superficial bladder carcinoma. Cancer. 2002;94:2363-2368.

17. Sylvester RJ, Oosterlinck W, van der Meijden AP. A single immediate postoperative instillation of chemotherapy decreases the risk of recurrence in patients with stage Ta T1 bladder cancer: a meta-analysis of published results of randomized clinical trials. J Urol. 2004;171: 2186-2190.

18. Babjuk M, Oosterlinck W, Sylvester R, Kaasinen E, Böhle A, Palou-Redorta J; European Association of Urology (EAU). EAU guidelines on non-muscle-invasive urothelial carcinoma of the bladder. Eur Urol. 2008;54:303-314.

19. Au JL, Badalament RA, Wientjes MG, et al; International Mitomycin C Consortium. Methods to improve efficacy of intravesical mitomycin C: results of a randomized Phase III trial. J Natl Cancer Inst. 2001;93: 597-604.

20. Dalton JT, Wientjes MG, Badalament RA, Drago JR, Au JL. Pharmacokinetics of intravesical mitomycin $\mathrm{C}$ in superficial bladder cancer patients. Cancer Res. 1991;51:5144-5152.
21. Kuroda M, Nijima T, Kotake T, Akaza H, Hinotsu S; 6th Trial of the Japanese Urological Cancer Research Group. Effect of prophylactic treatment with intravesical epirubicin on recurrence of superficial bladder cancer - The 6th Trial of the Japanese Urological Cancer Research Group (JUCRG): a randomized trial of intravesical epirubicin at dose of $20 \mathrm{mg} / 40 \mathrm{~mL}, 30 \mathrm{mg} / 40 \mathrm{~mL}, 40 \mathrm{mg} / 40 \mathrm{~mL}$. Eur Urol. 2004;45: 600-605.

22. Maeda T, Kikuchi E, Matsumoto K, Miyajima A, Oya M. Urinary $\mathrm{pH}$ is highly associated with tumor recurrence during intravesical mitomycin $\mathrm{C}$ therapy for nonmuscle invasive bladder tumor. $J$ Urol. 2011;185:802-806.

23. Groos E, Walker L, Masters JR. Intravesical chemotherapy. Studies on the relationship between $\mathrm{pH}$ and cytotoxicity. Cancer. 1986;58: 1199-1203.

24. Yen WC, Schmittgen T, Au JL. Different $\mathrm{pH}$ dependency of mitomycin C activity in monolayer and three-dimensional cultures. Pharm Res. 1996;13:1887-1891.

\section{Publish your work in this journal}

Drug Design, Development and Therapy is an international, peerreviewed open-access journal that spans the spectrum of drug design and development through to clinical applications. Clinical outcomes, patient safety, and programs for the development and effective, safe, and sustained use of medicines are a feature of the journal, which has also been accepted for indexing on PubMed Central. The manuscript management system is completely online and includes a very quick and fair peer-review system, which is all easy to use. Visit http://www.dovepress.com/testimonials.php to read real quotes from published authors.

Submit your manuscript here: http://www.dovepress.com/drug-design-development-and-therapy-journal 